\title{
Tracheal lesion during shoulder surgery: a case report and systemic review of the literature
}

\author{
Luigi Vetrugno ${ }^{1,2}$, Michele Divella ${ }^{2}$, Daniele Orso ${ }^{1}$, Cristian Deana ${ }^{2^{*}}$ (D), Giulia Vaccher ${ }^{1}$, Pietro Drovandi ${ }^{1}$,
} Alessandro Beltrame ${ }^{3}$, Araldo Causero ${ }^{1,3}$ and Tiziana Bove $e^{1,2}$

\begin{abstract}
Pneumomediastinum (PNM) and pneumothorax (PNX) are documented complications of arthroscopic shoulder surgery (ATS). Plexus anesthetic block and tracheal lesions during endotracheal intubation are hypothesized to be the underlying risk factors; however, the actual evidence supporting this hypothesis is scarce.

A case of bilateral laterocervical emphysema, subcutaneous edema, and signs of PNM after ATS performed under general anesthesia and supra-scapular nerve block is presented. An up-to-date systematic review of PNM/PNX during orthopedic surgery was performed, involving six databases: PubMed (1996-present), Embase (1974-present), Scopus (2004-present), SpringerLink (1950-present), Ovid Emcare (1995-present), and Google Scholar (2004present).

Twenty-five case studies met the eligibility criteria. In 24 cases, the patient underwent general anesthesia and orotracheal intubation; in 9 of these, a plexus anesthetic block was also performed. One case involved ATS under plexus anesthetic block only. In 10 cases, the diagnostic finding was PNM. In 5 cases, the diagnostic finding was associated with PNX. PNX was detected in 17 cases. In 2 cases, SE was found in the absence of any evidence of either PNM or PNX. A tracheal lesion was identified in 3 cases.

Endotracheal intubation and loco-regional anesthesia are not the only predisposing risk factors at play in the pathogenesis of PNM/PNX. Rather, multi-factorial pathogenesis seems more probable, necessitating that specific attention is paid during ATS to the change in patient position on the operating bed, to any slipping of the endotracheal tube, to patient monitoring whilst under the drapes, and to the cuff pressure. PROSPERO registration number: CRD42021260370.
\end{abstract}

Keywords: Arthroscopy, Pneumothorax, Pneumomediastinum, Subcutaneous emphysema, General anesthesia, Intubation, Shoulder surgery

\section{Introduction}

Pneumomediastinum (PNM) and pneumothorax (PNX) are rare but potentially fatal complications occurring during arthroscopic shoulder surgery (ATS). In the pathogenesis of PNM/PNX during ATS, three key risk factors have been hypothesized, namely (i) endotracheal

\footnotetext{
* Correspondence:

${ }^{2}$ Anesthesia and Intensive Care Department, ASUFC University Hospital of Udine, P.le S. M. Misericordia n. 15, 33100 Udine, Italy

Full list of author information is available at the end of the article
}

intubation, (ii) interscalene brachial plexus nerve block (ISB), and (iii) arthroscopic surgery itself. For instance, some have proposed lacerations of the trachea during endotracheal intubation or lesions of the parietal pleura during anesthetic block or surgery to constitute significant risk factors of PNM/PNX [1, 2]. However, evidence corroborating their involvement is scarce, and so they continue to be considered as hypotheses only.

As these three proposed etiopathogenetic conditions are often concomitant, we performed an analysis of all

(c) The Author(s). 2021 Open Access This article is licensed under a Creative Commons Attribution 4.0 International License, which permits use, sharing, adaptation, distribution and reproduction in any medium or format, as long as you give

appropriate credit to the original author(s) and the source, provide a link to the Creative Commons licence, and indicate if changes were made. The images or other third party material in this article are included in the article's Creative Commons licence, unless indicated otherwise in a credit line to the material. If material is not included in the article's Creative Commons licence and your intended use is not permitted by statutory regulation or exceeds the permitted use, you will need to obtain permission directly from the copyright holder. To view a copy of this licence, visit http://creativecommons.org/licenses/by/4.0/. 
case reports published in the last 30 years in order to verify the incidence of evidence of tracheal damage associated with ATS.

The aim of this review was to search the literature for all reported cases of PNM and PNX that occurred during orthopedic surgery in order to either corroborate the above-cited conditions (endotracheal intubation, ISB, and ATS) as probable risk factors or to exclude them as contributing to the pathogenesis of these complications. In addition to a literature review on this topic, a case report of tracheal rupture identified after general anesthesia for shoulder arthroscopy is presented.

\section{Case report}

A 54-year-old female patient was scheduled for rightshoulder arthroscopy due to a lesion of the supraspinatus tendon. The patient was obese (weight: $91 \mathrm{~kg}$; height $163 \mathrm{~cm} ;$ BMI $34 \mathrm{~kg} / \mathrm{m}^{2}$ ). No other illnesses were reported in her medical history. She was classified to have an ASA score of 2. No criteria for predicted difficult airway management were present.

Upon arrival in the operating room, standard monitoring indicated blood pressure at $140 / 80 \mathrm{mmHg}, \mathrm{HR} 70$ bpm, and $\mathrm{SpO}_{2} 98 \%$ while breathing room air. A largebore cannula (18 G) was placed in the left hand. With the patient in the sitting position, the supraspinous fossa was identified. Ultrasound long axis view with a linear probe (Esaote Mylab 25, linear probe $7.5 \mathrm{MHz}$ ) allowed identification of the floor of the fossa, with its characteristic "ice hockey stick" pattern. The tip of the needle (Pajunk, SonoPlex, $100 \mathrm{~mm}$ ), aiming at the most lateral part of the scapula, was visualized using the in-plane approach. US-guided suprascapular nerve block was induced with $15 \mathrm{~mL}$ of levobupivacaine $0.5 \%$. Subsequently, general anesthesia was induced with fentanyl $200 \mathrm{mcg}$, propofol $150 \mathrm{mg}$, and rocuronium $50 \mathrm{mg}$ after preoxygenation with a $\mathrm{FiO} 2$ of 0.8 . The laryngeal view obtained during laryngoscopy was classified as Cormack-Lehane grade 1 . The patient was intubated using a $7.5-\mathrm{mm}$ endotracheal tube with a high volume/ low-pressure cuff (MALLINCKRODT Hazelwood, USA) without a rigid stylet. The tracheal tube cuff pressure was measured using an analogical manometer, and set at $20 \mathrm{cmH}_{2} \mathrm{O}$. The patient was subsequently turned on to her left side.

Anesthesia was maintained with sevoflurane at an endtidal concentration (ET) of 1.6-1.8\% and fentanyl (100 $\mathrm{mcg}$ ). The surgical procedure lasted $1 \mathrm{~h}$ and $7 \mathrm{~min}$. After turning the patient supine at the end of the operation, anesthetic administration was stopped to allow the patient to emerge from anesthesia. Neuromuscular transmission recovered spontaneously (evaluated with TOFWatch, Organon, Dublin, Ireland). The woman showed signs of low tolerance to the endotracheal tube, with cough, irritability, and frequent head and neck movements; therefore, early extubation was performed after the endotracheal tube cuff had been completely deflated.

After $1 \mathrm{~h}$ of PACU stay, she was finally discharged onto the surgical ward. The Medical Emergency Team (MET) was called $6 \mathrm{~h}$ later because the patient presented latero-cervical subcutaneous emphysema (SE). Vital signs were within the normal range. The physician who visited her noticed left subcutaneous facial edema and mild crackling on palpation in the jugular region (Fig. 1). The patient reported a feeling of swelling; thus, a CT scan of the neck and thorax was performed to rule out the possibility of PNX. The CT scan showed bilateral latero-cervical SE, subcutaneous edema, and signs of PNM. No PNX was found. The patient was reassessed 6 $\mathrm{h}$ later on the same day by the same physician, who reported unchanged clinical conditions. Antibiotic treatment was started with amoxicillin/clavulanate $2.2 \mathrm{~g}$ every $6 \mathrm{~h}$. The patient underwent a bronchoscopy evaluation the day after, which revealed a likely iatrogenic submucous tracheal rupture, $6 \mathrm{~cm}$ below the vocal cords, in the pars membranacea, covered by fibrinous tissue (Fig. 2). No further treatment was required. She was finally discharged home after 5 days in good clinical conditions and without any SE.

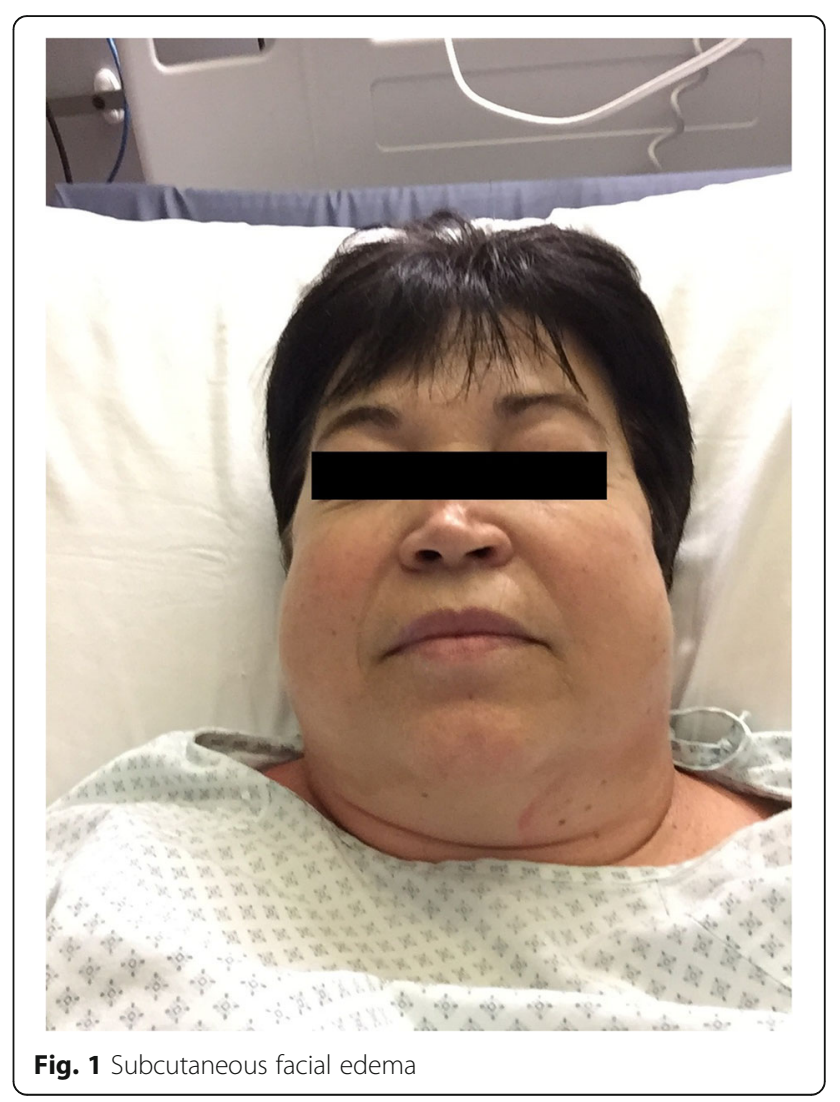




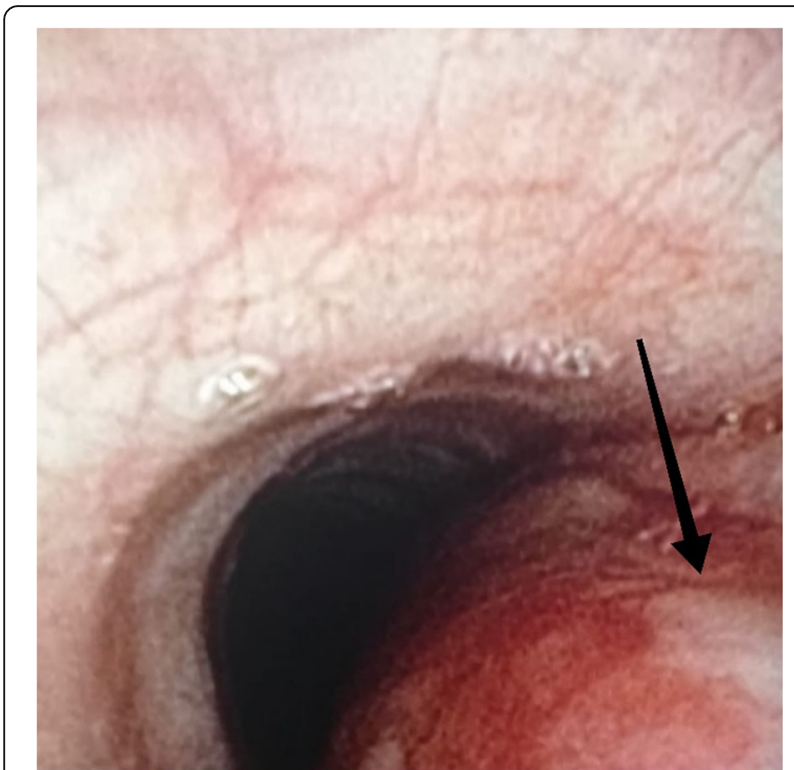

Fig. 2 latrogenic submucous tracheal rupture, $6 \mathrm{~cm}$ below the vocal cords, in the pars membranacea covered with fibrinous tissue that required no further treatment

\section{Methods}

A systemic review of the literature was performed to collect all case reports of patients undergoing orthopedic shoulder surgery ("population") and developing complications such as subcutaneous emphysema (SE), PNM, or PNX ("outcome"). Our goal was to compare the risk factors for SE/PNM/PNX for each reported case in order to establish the frequency of one or more risk factors occurring ("comparisons"). In conducting the review, AMSTAR 2 publication standards for systematic reviews were followed [3]. Six databases were screened: PubMed (1996-present), Embase (1974-present), Scopus (2004present), SpringerLink (1950-present), Ovid Emcare (1995-present), and Google Scholar (2004-present). The following keywords were used: "subcutaneous emphysema," "pneumomediastinum," "pneumothorax," "shoulder surgery," "intubation," and "emergency" to search each of the selected databases. Case studies published between 1990 and the present were considered. The literature review was registered on PROSPERO as CRD42021260370.

\section{Data extraction}

Two authors (MD and DO) retrieved the full texts of the relevant articles. All other related titles and abstracts were retrieved and their full versions obtained. The reference lists of the included studies and review articles were manually searched to identify any additional studies relevant to the analysis. Full-text documents were initially assessed for relevance and rapidly assessed using the Critical Appraisal Skills Program (CASP) checklist.
Articles that did not meet CASP's essential criteria (such as relevance to the review aim) were excluded from further analysis.

\section{Eligibility criteria}

Reported cases of SE, PNM, or PNX (including cases involving more than one of these conditions) as complications of orthopedic surgery were included ("intervention"). No age restrictions were considered.

\section{Exclusion criteria}

Studies involving non-human patients, preclinical research cases, research protocols, policy statements, and guidelines were excluded. Urgent interventions due to major trauma and associated with pre-existing pneumothorax of traumatic origin were not taken into account. Case reports on pediatric patients were also excluded.

\section{Summary of the literature}

Given the extreme heterogeneity of the case reports, we considered a quantitative synthesis to be unfeasible. We summarized the evidence from the literature by presenting the results of the individual studies included. We extracted and reported the following data for each of the case studies considered: the study's identification number, the age and sex of the patient, the reason for endotracheal intubation, the local anesthetic used, the time interval between possible injury and diagnosis, the presenting symptoms, diagnostic tests used, any evidence of tracheal injury and its location, treatments given, and prognosis.

\section{Results}

Twenty-five cases met the eligibility criteria (Fig. 3) [1, 4-20]. In twenty-four cases, the patient underwent general anesthesia and orotracheal intubation; in 9 of these, a plexus anesthetic block was also performed (Table 1). One case involved ATS in the absence of general anesthesia, which was instead performed under plexus anesthetic block only [2]. In 4 cases, the patient was male. Patient age ranged from 22 to 77 years. None of the cases experienced any form of intubation complications undergoing endotracheal intubation. In most cases, the first clinical manifestation (almost always the development of SE in the face or neck or a stinging sensation in the chest) occurred just after the patient had woken up from anesthesia or in the postoperative period. Only in one case did progressive arterial desaturation occur during surgery. In 10 cases, the diagnostic finding was PNM. In 5 cases, the diagnostic finding was associated with PNX. PNX was detected in 17 cases. In 2 cases, SE was found in the absence of any evidence of either PNM or PNX. A tracheal lesion was identified in 3 cases. In all cases, the outcome was benign, and the clinical 


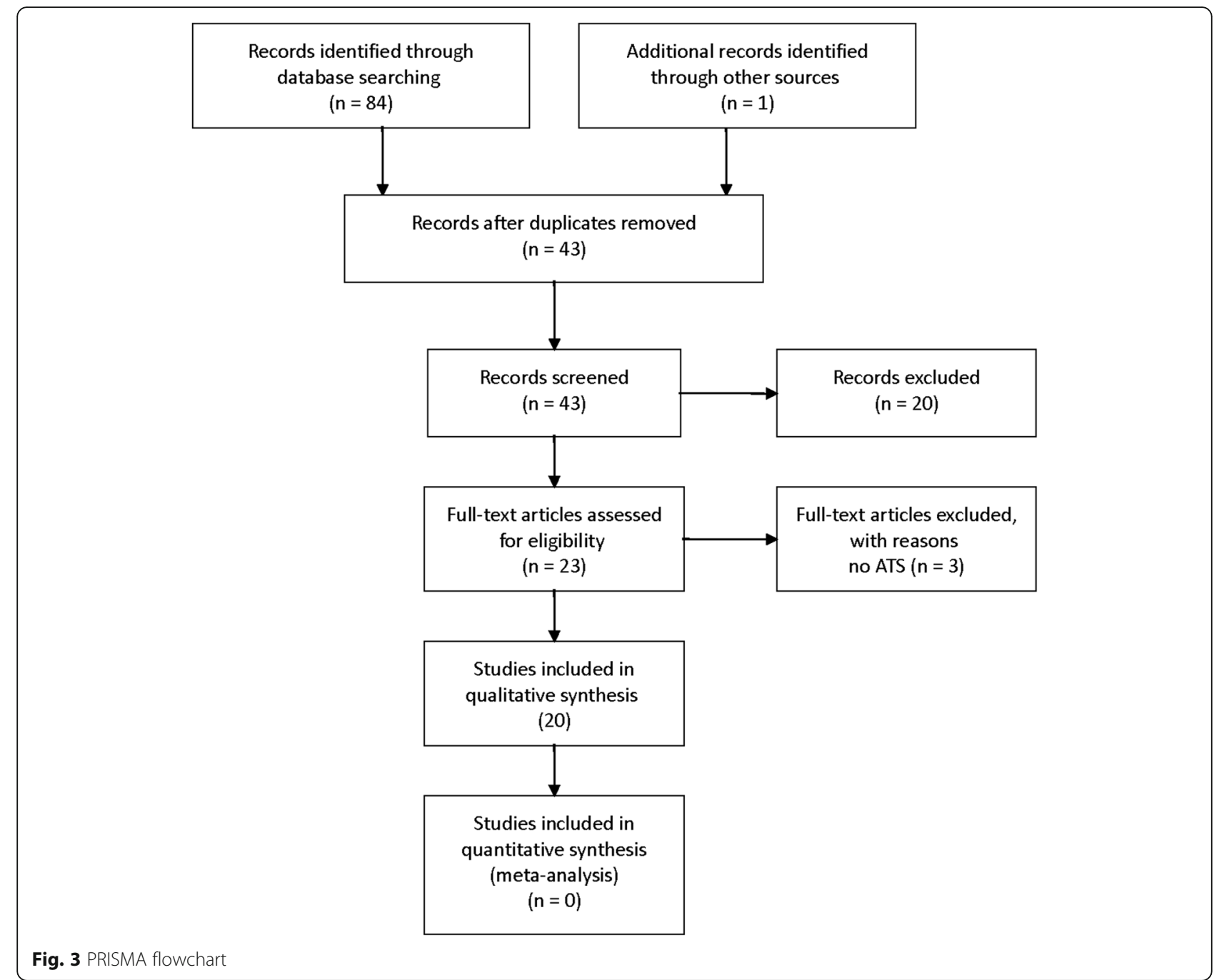

condition resolved conservatively (without any intervention). Regarding respiratory complications concerning anesthetic techniques, it emerged that SE/PNM after ATS under general anesthesia developed in 3 cases after an average of approximately $160 \mathrm{~min}$, whereas the average time needed to develop PNX was more than double that (542 min). Finally, it was found that in 19 cases, there were reported complications on the operated side (confirmed by radiographic investigation in 14 cases).

\section{Discussion}

It is customary to consider the possible development of SE, PM, or PNX during ATS due to direct pleural damage resulting from a complication of anesthetic block or laceration of the trachea during endotracheal intubation. However, these three pathological entities have also been reported in contexts other than ATS, either caused by tracheal damage-almost always associated with orotracheal intubation-or other causes. Sporadic cases secondary to barotrauma-for example, due to particularly vigorous Valsalva maneuvers, such as during the delivery or use of a laryngeal mask in spontaneous breathingcould induce other pathogenetic processes in addition to the direct pleural damage being considered [21, 22]. Furthermore, tracheal damage does not seem to be due to endotracheal intubation. Some signs of tracheal laceration found during ATS, even in patients not undergoing endotracheal intubation, seem to point toward causes other than endotracheal intubation [2]. In particular, three prime pathogenetic mechanisms are known to result in SE/PNM/PNX: (1) rupture of the parietal pleura, (2) rupture of the visceral pleura, and (3) alveolar rupture [2]. Alveolar rupture is the most common origin of PNX and may result from the rupture of a bleb. Rupture of the visceral pleura is considered a result of airway trauma during intubation. We speculate rupture of the parietal pleura to be the most frequent underlying cause of PNX; rupture may be related to the surgical methodology, to the subacromial distension used in ATS, or as a result of an anesthesia-related complication. The 


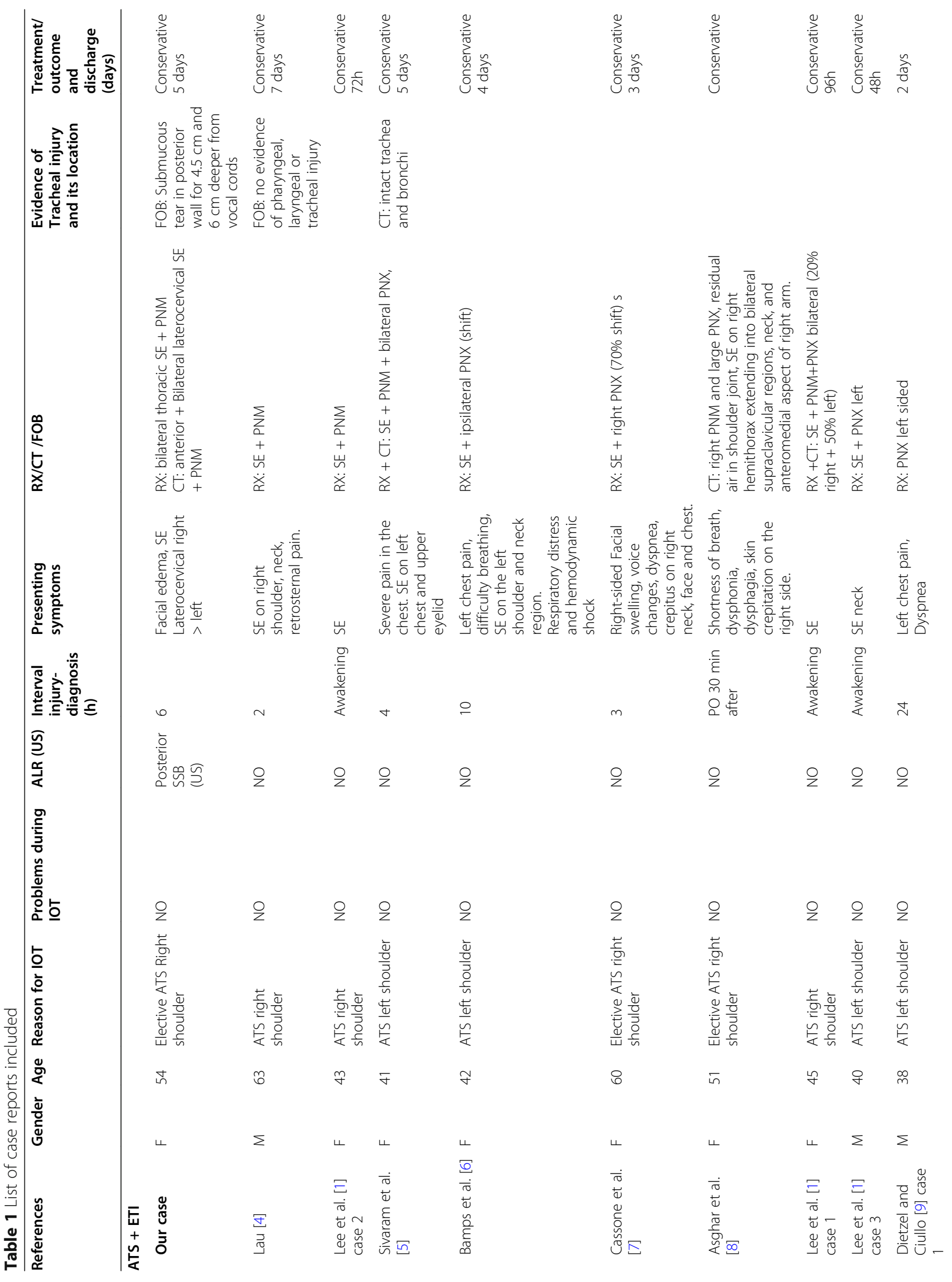




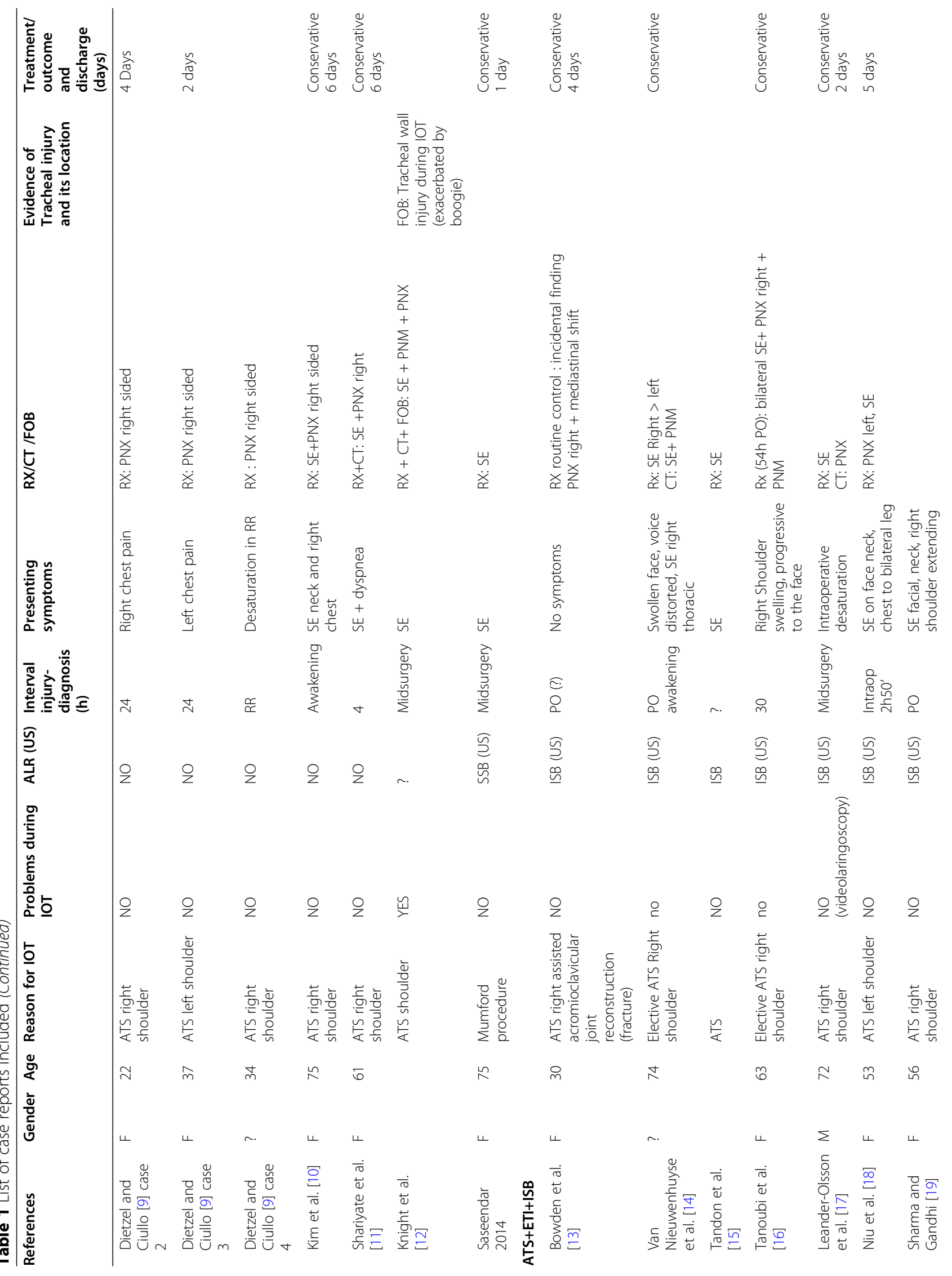




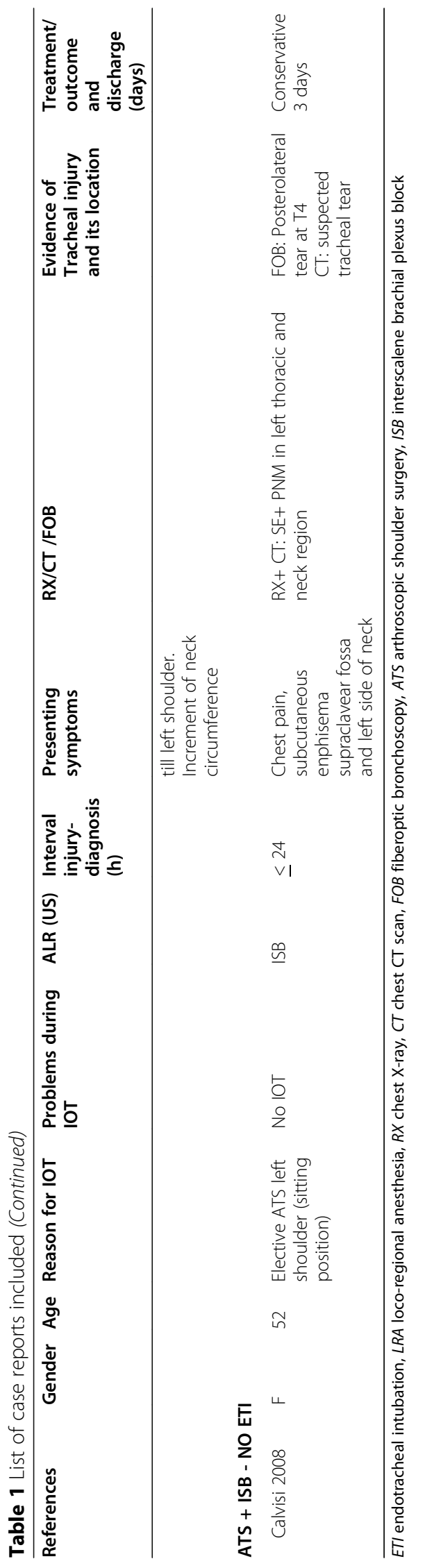


perforation of the parietal pleura during ISB is rare, occurring in approximately $0.2-0.3 \%$ of patients [6]. However, the incidence of PNX after ISB (0.2-3\%) is substantially higher than that of spontaneous PNX $(0.017 \%)$. An analysis of ISB alone without endotracheal intubation is not yet possible as only a single case has been reported in the literature to date [2]. To reduce the procedural risks related to ISB, evidence supports the use of suprascapular nerve block for shoulder surgery $[23,24]$.

SE is a condition in which air infiltrates the subcutaneous tissues. SE due to arthroscopy can be explained by transient changes in negative pressure in the subacromial space (SA) relative to atmospheric pressure. When the SA pressure is lower than atmospheric pressure due to the suction performed to remove debris, air can enter the SA space. The positive pressure of the infusion pump can subsequently push this air into the subcutaneous tissues after turning the suction off and thus cause SE. Air can enter the axillary sheath and extend through the prevertebral space of the neck surrounding the trachea and esophagus, causing PNM. Increased mediastinal pressure due to positive pressure ventilation or during exhalation can cause a rupture of the mediastinal parietal pleura and eventually PNX [14]. Lee et al. proposed an underlying mechanism of PNM/PNX that involves the arthroscopic pump and shaver system [1]. Intermittent pump infusion is typically used to maintain a relatively constant pressure (approximately $50 \mathrm{~mm} \mathrm{Hg}$ ) in the SA space. When the electric arthroscopic shaver is turned on with high intermittent suction, the pump infusion can continuously keep up with the suction and maintain constant pressure. If a transient pressure drop occurs in the SA, it may become negative relative to atmospheric pressure. The authors speculate that this transient pressure drop could cause air to enter the arthroscopic portals. When the electric shaver with suction is turned off, the positive pressure of the infusion pump may push air into the surrounding soft tissues, causing extensive SE. Air can enter the axillary sheath and prevertebral space of the neck, causing PNM. A further increase in mediastinal pressure due to positive pressure ventilation may cause a rupture of the parietal pleura, resulting in PNX.

Calvisi et al. reported a case of SE and PM after ATS [2]; they speculated a Bernoulli effect as the underlying cause, created by the pump, high-suction razor, and outflow cannula, similar to the mechanism proposed by Lee et al. [1].

The extravasation of the infusion fluid during the ATS procedure is another pathogenetic mechanism that can cause SE/PNM/PNX and air embolism, airway edema, and tracheal compression. The recognized risk factors include prolonged surgery, subacromial pathology, large irrigation volumes, increased working pressure, and obesity [25]. Some authors have reported an association between some of these factors, such as irrigation volume and surgical time, and a significant increase in the cuff pressure of the endotracheal tube without increasing the neck circumference [26]. However, only 5 of the 24 ATS case reports considered here investigated the integrity of the trachea through fiberoptic bronchoscopy or CT scan. None of the reported cases collected investigated risk factors of fluid extravasation during ATS.

Furthermore, according to this hypothesis, PNX could represent the end stage of a progression from $\mathrm{SE}$ and PNM. The timing of the onset of symptoms may correlate with the extent of the damage according to the sequence of $\mathrm{SE} \rightarrow$ PNM $\rightarrow$ PNX. About anesthetic techniques, the times to obtain a respiratory complication are longer with endotracheal intubation. Furthermore, the addition of ISB did not increase the incidence of reported events, even if the onset time for complications was significantly earlier (278 vs. $470 \mathrm{~min}$ ).

In order to confirm the pathogenetic hypothesis related to the ATS technique or ISB as a predisposing factor, additional data not available in the present series case reports would be necessary $[1,2]$.

In conclusion, the present analysis confirms that endotracheal intubation and loco-regional anesthesia are not the only predisposing risk factors at play in the pathogenesis of SE/PNM/PNX. Rather, multifactorial pathogenesis seems more probable, necessitating that specific attention is paid during ATS to the change in patient position on the operating bed, to any slipping of the endotracheal tube, to patient monitoring whilst under the drapes, and to the cuff pressure. In the future, it will be necessary to focus not only on the diagnosis of these complications but also on diagnostic investigations, such as $\mathrm{CT}$ of the neck, or fiberoptic bronchoscopy, aimed at obtaining the most precise information possible on the impact of ATS on the delicate cervicothoracic anatomical structures.

\section{Acknowledgements}

Not applicable.

\section{Authors' contributions}

LV conceived and designed the study; MD performed the medical digital library searches, drafted the article, and interpreted the data; DO performed the medical digital library searches and contributed toward drafting the article; CD critically reviewed the article; GV and PD acquired the data; $A C$ and $A B$ critically reviewed the article; and TB critically reviewed the article. All authors read and approved the final draft of the study.

\section{Funding}

None.

Availability of data and materials

Data sharing is not applicable to this article as no datasets were generated or analyzed during the current study. All case reports included in the review are available in Table 1. 


\section{Declarations}

\section{Ethics approval and consent to participate}

The need for approval was waived.

\section{Consent for publication}

Written informed consent was given prior to publication by the patient

\section{Competing interests}

Prof. Luigi Vetrugno declares to be an Associate Editor of the Journal of Anesthesia, Analgesia and Critical Care. The other authors declare that they have no competing interests.

\section{Author details}

'Department of Medicine, University of Udine, Via Colugna n. 50, 33100 Udine, Italy. ${ }^{2}$ Anesthesia and Intensive Care Department, ASUFC University Hospital of Udine, P.le S. M. Misericordia n. 15, 33100 Udine, Italy. ${ }^{3}$ Orthopedic and Trauma Department, ASUFC University Hospital of Udine, P.le S. M. Misericordia n. 15, 33100 Udine, Italy.

Received: 17 September 2021 Accepted: 15 October 2021

Published online: 26 October 2021

\section{References}

1. Lee HC, Dewan N, Crosby L (1992) Subcutaneous emphysema, pneumomediastinum, and potentially life-threatening tension pneumothorax. Pulmonary complications from arthroscopic shoulder decompression. Chest 101(5):1265-1267. https://doi.org/10.1378/chest.101. 5.1265

2. Calvisi V, Lupparelli S, Rossetti S (2009) Subcutaneous emphysema and pneumomediastinum following shoulder arthroscopy with brachial plexus block: a case report and review of the literature. Arch Orthop Trauma Surg 129(3):349-352. https://doi.org/10.1007/s00402-008-0593-y

3. Shea BJ, Reeves BC, Wells G, Thuku M, Hamel C, Moran J, Moher D, Tugwell P, Welch V, Kristjansson E, Henry DA (2017) AMSTAR 2: a critical appraisal tool for systematic reviews that include randomised or non-randomised studies of healthcare interventions, or both. BMJ 358:14008. https://doi.org/1 $0.1136 / \mathrm{bmj} . j 4008$

4. Lau KY (1993) Pneumomediastinum caused by subcutaneous emphysema in the shoulder. A rare complication of arthroscopy. Chest 103(5):1606-1607. https://doi.org/10.1378/chest.103.5.1606

5. Sivaram R, Shanmugasundaram S, Thangavel M, Mohammed EA (2020) Surgical emphysema following shoulder arthroscopy - a case report and review of a less recognized complication. J Arthrosc Surg Sports Med 1: 230-235. https://doi.org/10.25259/JASSM_23_2020

6. Bamps S, Renson D, Nijs S, Sermon (2016) Pneumothorax after shoulder arthroscopy: a rare but life-threatening complication. J Orthop Case Rep 6(4):3-5. https://doi.org/10.13107/jocr.2250-0685.542

7. Cassone MA, Kish KL, Nester JR, Hoffman LM (2020) Case report and literature review: post-arthroscopy pneumothorax with anterior decompression. Clin Pract Cases Emerg Med 4(4):580-583. https://doi.org/1 0.5811/cpcem.2020.8.48618

8. Asghar S, Azam M, Gjeka R, Adams A, Barakzai A, Maeza A, Kumar S (2015) Spontaneous pneumothorax with extensive subcutaneous emphysema: a rare complication of shoulder arthroscopy. Chest 148(4):34A. https://doi. org/10.1378/chest.2278764

9. Dietzel DP, Ciullo JV (1996) Spontaneous pneumothorax after shoulder arthroscopy: a report of four cases. Arthroscopy 12(1):99-102. https://doi. org/10.1016/S0749-8063(96)90228-5

10. Kim JB, Choi MK, Jeon YK, Lee JM (2017) Chest wall swelling and pneumothorax after shoulder arthroscopy: were the 2 events totally independent? Medicine (Baltimore) 96(21):e7020. https://doi.org/10.1097/MD. 0000000000007020

11. Shariyate MJ, Kachooei AR, Ebrahimzadeh MH (2017) Massive emphysema and pneumothorax following shoulder arthroscopy under general anaesthesia: a case report. Arch Bone Jt Surg 5(6):459-463

12. Knight KM, Martin G, Imbuldeniya AM (2011) Surgical emphysema of the neck following arthroscopic shoulder surgery. Br J Hosp Med (Lond) 72(12): 712-713. https://doi.org/10.12968/hmed.2011.72.12.712

13. Bowden BD, Williams WA, Stumpo LA, Stephens SP, DeCoons RM (2020) Large asymptomatic pneumothorax following arthroscopic-assisted acromioclavicular joint reconstruction after ultrasound-guided interscalene block: a case report. JSES Int 4(3):551-554. https://doi.org/10.1016/j.jseint.202 0.02 .013

14. Van Nieuwenhuyse ES, Kerens B, Moens J, Kiekens G (2017) Subcutaneous emphysema after shoulder arthroscopy. A case report and review of the literature. J Orthop 14(2):287-289. https://doi.org/10.1016/j.jor.2017.03.009

15. Tandon S, Taxak S, Gupta KB, Janmeja AK (1998) Pneumomediastinum: a rare complication of brachial plexus block. Indian J Chest Dis Allied Sci 40(3):217-219

16. Tanoubi I, Drolet $P$, Blanchette D (2010) Emphysème sous-cutané et pneumothorax tardifs à la suite d'une arthroscopie de l'épaule [Late subcutaneous emphysema and pneumothorax after shoulder arthroscopy]. Can J Anaesth 57(4):383-384. https://doi.org/10.1007/s12630-009-9258-8

17. Leander-Olsson O, Borglund-Hemph A, Jakobsson JG (2016) Pneumothorax following shoulder arthroscopy under combined regional and general anaesthesia-a case report. Int J Surg Case Rep 24:73-76. https://doi.org/10.1 016/j.ijscr.2016.05.012

18. Niu WY, Liao YA, Liu SC, Liu YC, Lin FS (2020) Air-driven drill induced diffuse subcutaneous emphysema and pneumothorax during shoulder arthroscopic surgery. Asian J Anesthesiol 58(1):50-53. https://doi.org/10. 6859/aja.202003_58(1).0007

19. Sharma V, Gandhi R (2020) Fast-track management of airway complications following shoulder arthroscopy. Ain-Shams J Anesthesiol 12(1):49. https:// doi.org/10.1186/s42077-020-00099-2

20. Saseendar S, Tan SH, Vijayan S, Pawaskar A, Kumar VP (2016) Extensive subcutaneous emphysema complicating a percutaneous Mumford procedure. Knee Surg Sports Traumatol Arthrosc 24(6):1907-1910. https:// doi.org/10.1007/s00167-014-3183-2

21. Brussa A, Marangone A, Vetrugno L, Dogareschi T, Bove T (2019) Spontaneous postpartum pneumomediastinum: beware of too much diagnostics. J Thorac Dis 11(3):E34-E36. https://doi.org/10.21037/jtd.2019. 02.42

22. Choy MC, Pescod D (2007) Pneumothorax in association with spontaneous ventilation general anaesthesia--an unusual cause of hypoxaemia. Anaesth Intensive Care 35(2):270-273. https://doi.org/10.1177/0310057X0703500218

23. Hussain N, Goldar G, Ragina N, Banfield L, Laffey JG, Abdallah FW (2017 Dec) Suprascapular and interscalene nerve block for shoulder surgery: a systematic review and meta-analysis. Anesthesiology. 127(6):998-1013. https://doi.org/10.1097/ALN.0000000000001894

24. Divella M, Vetrugno L, Orso D, Langiano N, Bignami E, Bove T, Della RG (2019 Apr) Interscalene versus suprascapular nerve block: can the type of block influence short- and long-term outcomes? An observational study. Minerva Anestesiol. 85(4):344-350. https://doi.org/10.23736/S0375-9393.18.12 791-X

25. Bhaskar SB, Manjuladevi M (2015) Shoulder arthroscopy and complications: can we afford to relax? Indian J Anaesth 59(6):335-337. https://doi.org/10.41 03/0019-5049.158729

26. Choi HR, Kim S, Kim HJ, Ahn EJ, Kim KW, Bang SR (2020) Aumento da pressão do balonete do tubo endotraqueal em pacientes submetidos a artroscopia do ombro: estudo de coorte [Endotracheal tube cuff pressure increases in patients undergoing shoulder arthroscopy: a single cohort study]. Rev Bras Anestesiol 70(6):583-587. https://doi.org/10.1016/j.bjan.2020. 04.021

\section{Publisher's Note}

Springer Nature remains neutral with regard to jurisdictional claims in published maps and institutional affiliations.

Ready to submit your research? Choose BMC and benefit from:

- fast, convenient online submission

- thorough peer review by experienced researchers in your field

- rapid publication on acceptance

- support for research data, including large and complex data types

- gold Open Access which fosters wider collaboration and increased citations

- maximum visibility for your research: over $100 \mathrm{M}$ website views per year

At $\mathrm{BMC}$, research is always in progress.

Learn more biomedcentral.com/submission 